\title{
Sexual Assault Among College Students Attending a Historically Black College/University
}

\author{
Deshawn Collington*, Markea Carter, Aliyah Tolliver, \& Jocelyn Turner-Musa \\ Department of Psychology, Morgan State University, Baltimore, MD \\ https:// doi.org/10.33697/ajur.2019.004 \\ Students:d.collington11@gmail.com*,marcar26@morgan.edu,tolliveraliyah17@gmail.com \\ Faculty Advisor: Jocelyn.turnermusa@morgan.edu
}

\begin{abstract}
Sexual assault constitutes a significant public health problem on college campuses including historically Black colleges and universities (HBCU). Recent research suggests that sexual assault is increasing on college campuses. However, there are few studies examining the prevalence and risk factors for sexual assault at HBCUs. To address this gap, the current study examined the prevalence, correlates, and outcomes of sexual assault at an HBCU. Participants in the study were 264 undergraduate students from an $\mathrm{HBCU}$ in the mid-Atlantic region. The majority of participants were female (71\%), African American (91\%), and seniors (41\%). After providing informed consent, participants completed a Climate Assessment survey administered by the university's Office of Diversity. Findings revealed that since starting college about $20 \%$ of students experienced sexual contact without consent. Of those sexually assaulted, $20 \%$ reported they were incapacitated or under the influence of alcohol (15\%) at the time of the assault. About $17 \%$ of those assaulted experienced a physical injury and/or poor mental health outcomes (e.g., anxiety, depression, flashbacks). Participants reported not disclosing information of their assault due to embarrassment, afraid of retaliation from the perpetrator, believing it was a private matter. Close friends were more likely to be told about sexual assault. The study supports the need to address sexual assault on HBCU campuses through strong prevention and intervention programs and to address barriers to reporting.
\end{abstract}

\section{KEYWORDS}

Sexual Assault; HBCU; College Students; Prevalence; Risk Factors; Outcomes; Barriers of Reporting; Sexual Assault Climate Assessment Survey

\section{INTRODUCTION}

Sexual assault is defined as any sexual acts committed against someone without that person's freely given consent. ${ }^{1}$ It can be categorized as sexual activities such as incest, molestation, fondling, or forced sexual intercourse. ${ }^{2}$ Women between the ages of 18 and 24 are at a higher risk of experiencing sexual assault. ${ }^{3}$ Sexual assault remains a problem on college campuses, particularly among women. ${ }^{4}$ Unfortunately, most studies examining sexual assault focus on predominately white (PWI) college campuses and not minority-serving institutions. This paper reviews the extant literature on sexual assault, general findings on studies of sexual assault on college campuses, and a review of findings from those few studies that examine sexual assault at HBCUs.

Sexual Assault in the U.S.

According to the Rape, Abuse, and Incest National Network (RAINN, 2016), every 107 seconds, an American is sexually assaulted. ${ }^{3}$ The U.S. Department of Justice's National Crime Victimization Survey (as cited in RAINN, 2016) reported there is an average of 293,066 victims (age 12 or older) of rape and sexual assault each year. ${ }^{3}$ Approximately $19.3 \%$ of women have experienced rape and $43.9 \%$ experienced other forms of sexual assault-including unwanted sexual contact (i.e., kissing or touching) or sexual coercion. ${ }^{5}$ About $3 \%$ of American men or 1 in 33 have experienced attempted or completed rape in their lifetime. 2 out of 3 sexual assault incidents are not reported to the police. ${ }^{3}$ The LGBTQ community is also affected by sexual assault; $46.4 \%$ lesbians, $74.9 \%$ bisexual women and $43.3 \%$ heterosexual women have experienced sexual violence other than rape during their lifetime. ${ }^{6}$ Cumulatively, these findings suggest that sexual assault is a problem in the U.S. and that there is a need to explore and better understand risk factors for sexual assault among at-risk populations, such as college students.

Sexual Assault on College Campuses

College and university administrators, faculty, staff, and students are aware of campus sexual assault, yet it remains a significant problem on college campuses. One in five women and one in 16 men are sexually assaulted while in college..$^{7}$ A study done by Jordan, Combs, and Smith (2014) examining sexual assault and academic performance found that more than $40 \%$ of the female participants had experienced rape or sexual assault during their teen years. ${ }^{8} 24 \%$ of women experienced sexual victimization 
during their first semester of college in addition to another $20 \%$ during their second semester of college. It is common that college-aged female victims know their offender in about $80 \%$ of rape and sexual assault victimization. ${ }^{9}$ Although women are more likely to be victims of sexual assault, a Campus Sexual Assault study (CSA) found that approximately $6.1 \%(\mathrm{n}=84)$ of males reported experiencing attempted or completed sexual assault since entering college. Half of them $(n=50,3.7 \%)$ experienced a completed sexual assault. Incapacitation of the victim is more prevalent among women. Incapacitation involves the use of alcohol or drug use, being passed out, asleep, or being unable to consent regardless of the perpetrator being responsible or the victim's own actions to participate in substance use. ${ }^{10} 7.8 \%$ of women $(\mathrm{n}=466)$ were victims of alcohol or drug enabled sexual assault. $0.6 \%$ of women $(n=31)$ were victims of confirmed drug-facilitated sexual assault while $1.7 \%(n=103)$ were victims of suspected drug-facilitated sexual assault. 1.0\% $(\mathrm{n}=48)$ were unable to provide consent. According to the College Alcohol Study (CAS), 3.4\% of women who were raped were unable to provide consent due to incapacitation and $3.1 \%$ experienced drug-facilitated sexual assault (DFSA). ${ }^{10}$

Sexual assault is highly underreported. Evidence shows victims are more likely to disclose to friends and less likely to formally report the incident to authorities. For instance, a study found that in $2 / 3 \mathrm{rds}$ of incidents, the victim disclosed to another person, usually a friend, but not family or school officials. ${ }^{11}$ Sable, Danis, Mauzy, and Gallagher (2006) described psychological and legal barriers that have discouraged college students who are victims of sexual assault from reporting. ${ }^{12}$ This study identified 13 barriers to reporting for women and 14 for men. Each characterized which barrier were reasons to not report by importance. Women's barriers to reporting included fear of retaliation by the perpetrator, financial dependence, did not want family or friend to be prosecuted, and lack of resources to obtain help. Men's barriers to reporting included shame, embarrassment, confidentiality concerns, and fear of not being believed. Many women often may not report because they know the perpetrator. Men are less likely to report due to masculinity stereotypes. Alcohol and drug use are another factors that explains college students not reporting to law enforcement. ${ }^{13}$ Self-blame typically occurs when the victim was under the influence. ${ }^{14}$ Alcohol seems to be a key contributor in campus sexual assault. ${ }^{15}$ Typically, both the perpetrator and the victim had consumed alcohol. Abbey, McAuslan, and Ross (1998) reported that $42 \%$ consumed alcohol prior to the incident and 53.4\% reported that the perpetrator had consumed alcohol prior to the incident. ${ }^{16}$ Alcohol effects on motors skills may limit women's ability to resist sexual assault attempts. It also affects perceptions of responsibility. Alcohol consumption among men is perceived to be justification for inappropriate behavior allowing them to feel comfortable when engaging in such risky behaviors. However, some women who consume alcohol may take the blame for sexual assault. ${ }^{15}$ These findings suggest that sexual assault is a problem on college campuses and must be addressed. Moreover, most of the research reviewed has focused on predominately White college campuses. While it is important to study sexual assault regardless of the type of campus, there is a need to examine the prevalence and outcomes of sexual assault on all college campuses, including Historically Black Colleges and Universities (HBCU).

\section{Sexual Assault at HBCUs}

As cited above, there is an extensive amount of research focusing on sexual assault targeting students at Predominately White Institutions (PWI) however, limited research exists addressing sexual assault among students attending minority-serving institutions such as Historically Black Colleges and Universities (HBCU) ${ }^{17}$ Research suggests that there may be differences in sexual assault rates between these institutions. Differences between African American women at non-HBCUs to those at HBCUs is unknown..$^{18}$ According to Lindquist et al. (2013), approximately $9 \%$ of undergraduate women had experienced physically forced sexual assault prior to entering college. 3.4\% experienced incapacitated sexual assault and $2.4 \%$ experienced both prior and since entering college. ${ }^{18}$

The goal of the HBCU- Campus Sexual Assault (HBCU-CSA) study was to document information on prevalence, consequences, and risk factors of sexual assault among African American college students. ${ }^{19}$ This study included 3,951 women from four HBCUs. $14.9 \%$ reported experiencing attempted or completed sexual assault prior to entering college. $14.2 \%$ reported experiencing attempted or completed sexual assault since beginning college. $3.8 \%$ of women experience physically forced rape, and $4.8 \%$ experienced rape while incapacitated and unable to provide consent. Prevalence estimates of victims suggest that some were incapacitated and unable to provide consent. $4.0 \%$ of women were victims of alcohol or other drugs (AOD) which includes the victim voluntarily consuming alcohol prior to the incident and $0.3 \%$ were victims of DFSA. Rates of sexual assault when the victim was incapacitated and unable to provide consent appears to be considerably lower for women at HBCUs than nonHBCUs.

The HBCU-CSA study also examined risk factors among victims of sexual assault at an HBCU. Prior victimization is associated with experiencing sexual assault after entering college. Women dating at least one person after entering college compared to those not dating were more likely to experience any type of sexual assault. Compared to women with no male sexual partners, women who had between one and five male sexual partners since entering college were more likely to experience incapacitated sexual assault and those with more than five male sexual partners were more likely to experience all types of sexual assault. Women who reported getting drunk were likely to be victims of incapacitated sexual assault. The study described individual and behavioral risk 
factors associated with sexual assault. The type of sexual assault was associated with a given risk factor. Factors such as prior victimization and party attendance were associated with physically forced sexual assault. Behavioral influences such as substance use and depression were associated with incapacitated sexual assault. Victims of incapacitated sexual assault reported engaging in alcohol or drugs prior to the incident. Other risk factors such as accepting drinks from strangers or sorority membership were associated with both forced and incapacitated sexual assault since entering college.

Women victimized by sexual assault were found to have significantly more symptoms of depression and were more likely to experience post-traumatic stress disorder (PTSD) compared to women who had not been sexually assaulted. ${ }^{18}$ Sexual assault victims were more likely to report the incident to family, friends, law enforcement, or crisis centers. Victims were also more likely to drop their classes, change majors, or seek counseling.

Given the limited amount of literature to address sexual assault on an HBCU campus, the current study attempted to answer the following questions:

1. What is the prevalence of sexual assault on an HBCU campus?

2. What are the correlates associated with sexual assault at an HBCU?

3. What are the outcomes associated with sexual assault at an HBCU?

4. What are the reporting practices and barriers to reporting sexual assault at an HBCU?

\section{METHODS AND PROCEDURES}

\section{Participants}

Participants were 264 undergraduate students attending a co-ed HBCU located in the northeast region of the US. Among the participants, $71.7 \%$ were female and $28.9 \%$ male. A majority of participants were African American (90.9\%), $4.3 \%$ were Caucasian, $4.2 \%$ were Hispanic or Latino, 3\% were American Indian or Alaska Native., 2.7\% were Asian and 1.1\% Native Hawaiian or Pacific Islander. Most participants were seniors (40.9\%), $22 \%$ were juniors, $21.2 \%$ were freshmen and 15.2\% were sophomores. Participant ages ranged between $18-24.11 \%(n=29)$ were 18 years of age, $16.3 \%(n=43)$ were 19, 15.2\% $(n=40)$ were $20,17.8 \%(\mathrm{n}=47)$ were $21,11.7 \%(\mathrm{n}=31)$ were $22,9.8 \%(\mathrm{n}=26)$ were 23 and $18.2 \%(\mathrm{n}=48)$ were 24 or older. $79.2 \%$ were heterosexual, and $2.7 \%$ were gay. Approximately $39.2 \%$ reported living in a college residence hall and $4.6 \%$ living on-campus. $94.3 \%$ of participants were full-time students and $5.3 \%$ were part-time.

\section{Procedures}

The university's Office of Diversity submitted and received IRB approval to administer a campus-wide Climate Assessment Survey developed by an educational technology company which offers online training on various topics including sexual assault prevention. The survey instrument is based on a model template provided by the White House Task Force Report to Protect Students from Sexual Assault ${ }^{20}$. The survey was administered during the 2015-2016 academic year. Permission to assist with recruitment, data collection, and to utilize data from the study was granted to the student investigators from the Office of Diversity. All undergraduate students were recruited via email which included a hyperlink to the online questionnaire. Participants were also recruited via convenience sampling, flyers on social media. The online questionnaire remained available from December 2015 to February 2016. The home page of the study included a description of the study and allowed students to indicate their consent by clicking yes or no to proceed. The participants' identities remained anonymous throughout the survey and they were given the option to withdraw-or skip questions at any time without penalty. To ensure confidentiality and anonymity, participants were given a link to a site that would delete their web browsing history after completing the survey. The online survey was approximately $30-45$ minutes. After completion of the survey, on and off campus resources were provided for mental health services and sexual assault/relationship violence support in case of any discomfort. Participants were then directed to another link to participate in a raffle to win a notebook computer. All participants were thanked for their participation.

\section{Measure}

A web-based Campus Climate Survey was developed by an educational consulting company and aimed to identify the prevalence, perceptions of campus policies and reporting, risk factors, and outcomes of sexual assault on campus. The climate survey consisted of 14 sections with a total of 101 questions. For the purposes of this study, only three sections were analyzed:

1. Demographics: This section asked background information such as biological sex, race, classification, living arrangements, and enrollment status.

2. Alcohol and Drug Use: This section asked participants about their experiences with alcohol and drugs. Drinking or other under the influence at the time of the incident. A Sample item include "since the beginning of this school year, about how often have you consumed alcohol?" Participants responded to the frequency in 
which they engaged in a behavior from $1=$ Never, $2=$ Less than once month $/ \mathrm{A}$ few times, $3=$ Once or twice a month, 4=Once or twice a week, and 5= Daily or almost daily.

3. Sexual Violence: This section asked questions about the nonconsensual sexual contact which targeted five types of sexual contact (oral sex, touching of a sexual nature, sexual intercourse, anal sex and sexual penetration with a finger or object). Sample items include, "have you experienced sexual contact without your consent since you became a student or just prior to the incident." In addition, items measured outcomes and barriers of reporting such as "did the incident have a negative impact on the following "(i.e., schoolwork, social activities, or social relationships). Items were measured using yes/no responses, and multiple response options (i.e., check all that apply).

\section{Study analyses}

This study is a descriptive study that captures information involving unwanted sexual experiences of students. Descriptive analyses were conducted to identify participants' demographics, prevalence rates, risk factors, and barriers to reporting associated with sexual assault and the outcomes of victimizations. Chi-square analysis was done to determine the prevalence rates of sexual assault by gender and classification.

\section{RESULTS}

Prevalence of Sexual Assault at an $\mathrm{HBCU}$

Prevalence estimates of sexual assault prior to and since entering college was determined. Past research suggests that experience of sexual assault prior to college is a correlate of sexual assault occurring during college. Of the 264 participants, completing the survey, 174 responded to questions about sexual assault. Of these students, $25.3 \%(n=44)$ reported having experienced sexual contact without consent before becoming a college student. 20.6\% $(n=34)$ reported experiencing sexual contact without their consent since becoming a student. 17.6\% $(\mathrm{n}=6)$ reported experiencing completed sexual contact through physical force or threats prior to entering college, $20.6 \%(n=7)$ reported after the start of the 2015 academic year and $11.8 \%(n=4)$ said both before and since the start of the academic year. $14.3 \%(n=5)$ had experienced attempted sexual contact by physical force or threats, $11.4 \%$ $(n=4)$ after the start of the academic year and 8.6\% $(n=3)$ both before and after the academic year. As shown in Table 1, women were significantly more likely to report sexual assault compared to men; $x^{2}(1)=9.47, \mathrm{p}<.01$. Table 2 shows that upperclassmen were more likely to report being sexually assaulted compared to lowerclassmen; $x^{2}(1)=3.99, \mathrm{p}<.05$. Since becoming a student, $20.2 \%$ reported experiencing verbal or non-physical coercion and a smaller percentage reported attempted verbal or non-physical coercion (11.4\%). Since becoming a student, $6.1 \%$ suspected that someone had sexual contact with them when they were unable to provide consent or incapacitated, and $9.1 \%$ had experienced someone having sexual contact with then while being unable to provide consent or incapacitated.

\begin{tabular}{|c|c|c|c|c|}
\hline \multirow[b]{2}{*}{ Responses } & \multicolumn{2}{|c|}{ Female } & \multicolumn{2}{|c|}{ Male } \\
\hline & $\mathrm{N}$ & $\%$ & $\mathrm{~N}$ & $\%$ \\
\hline Yes & 31 & 26 & 3 & 6 \\
\hline No & 74 & 89 & 50 & 94 \\
\hline
\end{tabular}

Table 1. Prevalence of sexual assault since becoming a student by gender. 21 students did not report their gender.

$x^{2}(1)=9.47, \mathrm{p}<.01$

Yes

No

\begin{tabular}{lcccc}
\cline { 2 - 4 } Classification & $\mathrm{N}$ & $\%$ & $\mathrm{~N}$ & \\
\hline Lower Classmen & 7 & 12 & 54 & 88 \\
Upper Classmen & 27 & 24 & 85 & 76
\end{tabular}

Table 2. Prevalence of sexual assault since becoming a student by classification. Lower classmen represent freshman and sophomores. Upperclassmen represent juniors and seniors.

$x^{2}(1)=3.99, \mathrm{p}<.05$ 
Correlates Associated with Sexual Assault

Of the 34 participants who reported experiencing sexual assault since becoming a student, as shown in Figure 1, 5 participants $(15 \%)$ had been drinking alcohol just prior to the incident, 3 participants $(8 \%)$ were drunk, and 7 participants $(20 \%)$ had been incapacitated and not able to give consent or stop what was happening. Participants were also asked who had the unwanted sexual contact with them. $10.2 \%$ said it was a male and $1.1 \%$ female. Victims also reported whether the incident involved the other person's use of alcohol (44.8\%) or drugs (83.3\%), and their own use of alcohol (20.7\%) or drugs (96.7\%). From these results, alcohol consumption and drug use are a contributing factor to sexual assault.

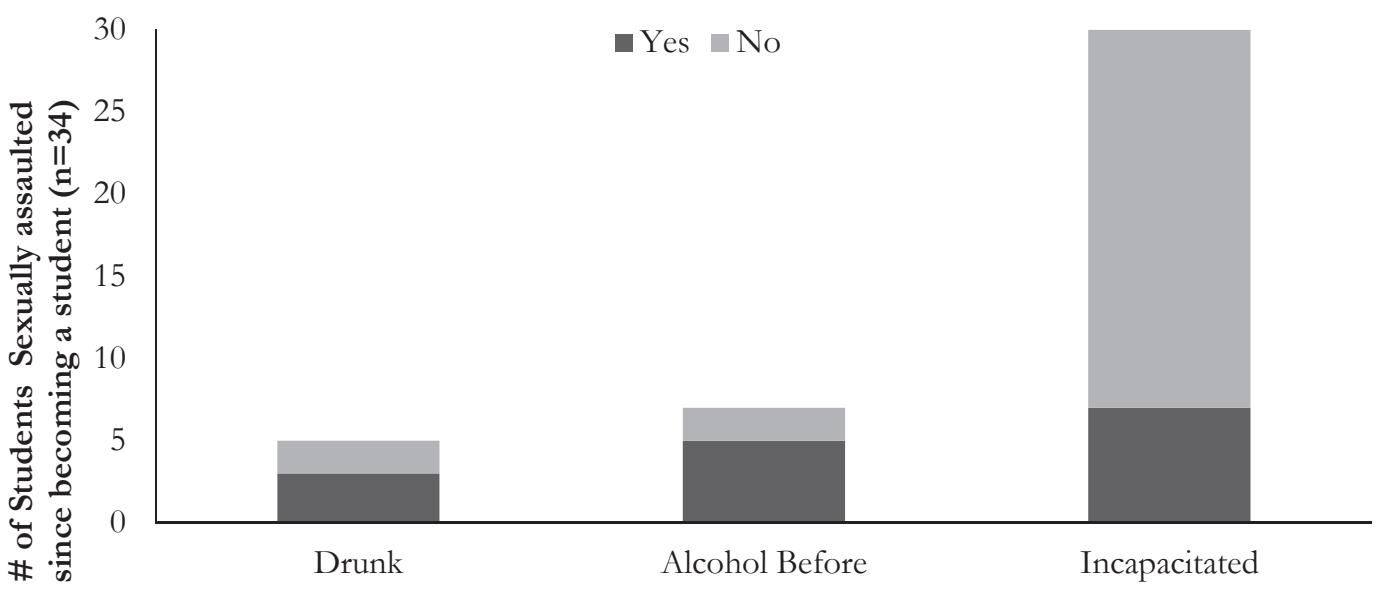

Figure 1. Alcohol-invloved correlates associated with sexual assault

Outcomes Associated with Sexual Assault

$17.2 \%$ of victims reported physical injury after the incident. Many of them faced sexual trauma outcomes presented in Figure 2. The highest reported was anxiety $(70.4 \%)$ and the lowest was alcohol or substance use $(15.4 \%)$. As a result of the incident, victims reported being behind in their schoolwork, performing poorly on assignments, or missing a class. The incident also had a negative impact on their jobs, social activities, and intimate relationships. 22.2\% sought medical treatment after the incident, $25.9 \%$ sought counseling services and $7.4 \%$ sought advocacy services.

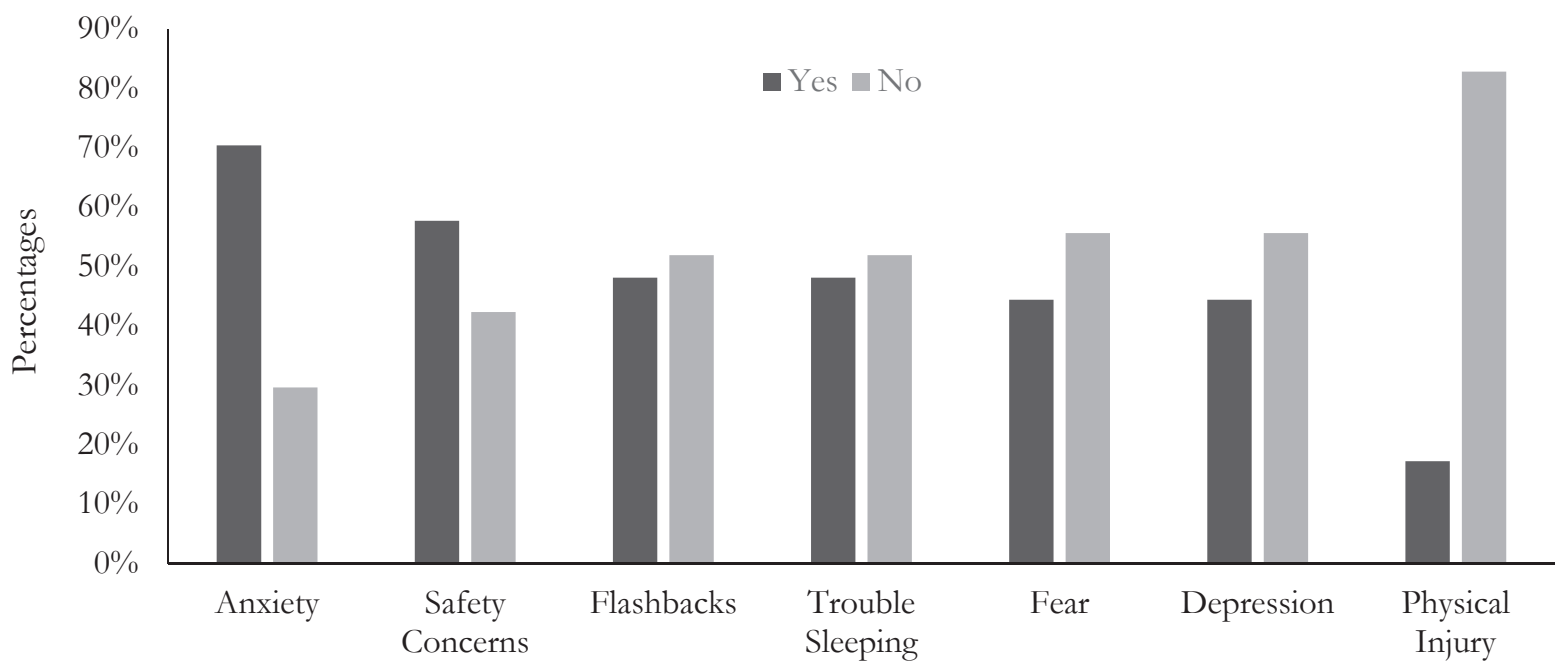

Figure 2. Reported outcomes associated with victims of sexual assault. 
Barriers of Reporting Sexual Assault

Approximately $22 \%$ of the sample reported a lack of knowledge of where to get help regarding sexual assault resources on campus. $24 \%$ did not understand how to report a sexual assault on campus. Victims were asked who they told about the incident of sexual assault as shown in Figure 3. The majority had told a close friend other than a roommate or no one and were least likely to report to police or campus faculty. Victims were also asked why the chose not to report their assault as presented in Figure 4. Answers varied from embarrassment, wanting to deal with it on their own, afraid of retaliation, didn't want the offender to get in trouble, or afraid of not being believed.

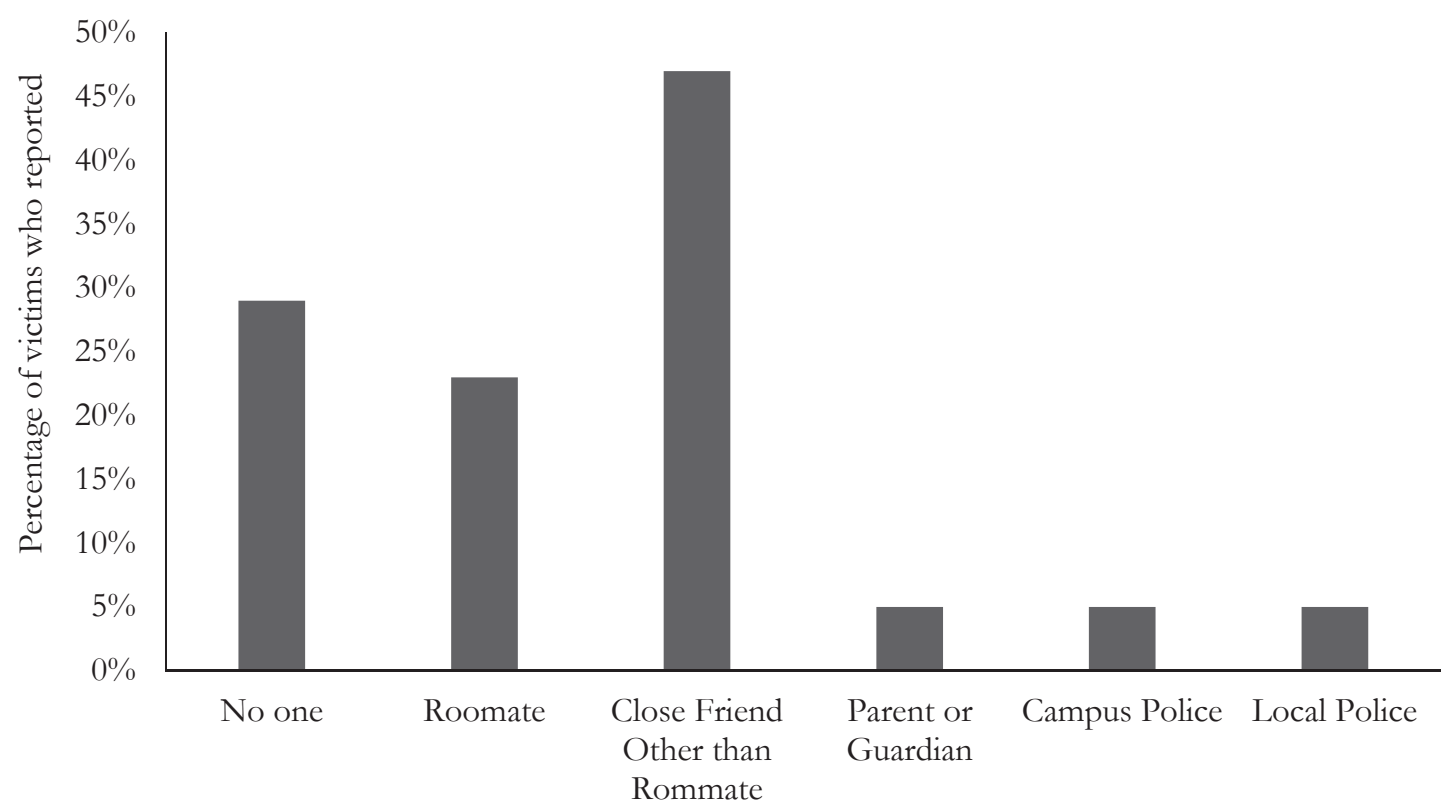

Figure 3. Reporting of sexual assault. Percentages are represented by those who reported being sexually assaulted.

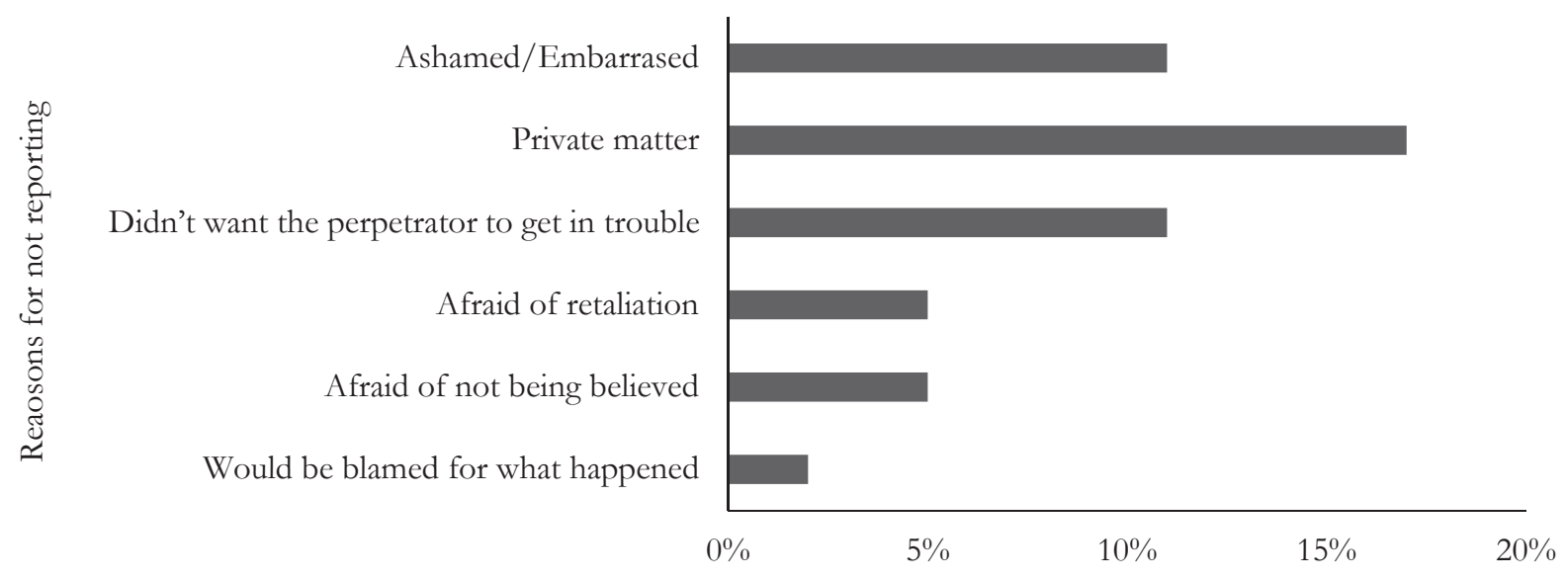

Figure 4. Percentages are represented by those who reported being sexually assaulted.

\section{DISCUSSION}

The purpose of the study was to identify prevalence rates, correlates, outcomes, and barriers to reporting sexual assault at an HBCU. Our results suggest that since starting college about $20 \%$ of student surveyed experienced sexual contact without consent. This finding is similar to previous research studies examining sexual assault among college students. For example, similar to Krebs et al. (2007) and Sinozich \& Langton (2014) 20\% of undergraduate women attending a PWI reported experiencing sexual assault 
since entering college.9,10 Also, consistent with previous research suggesting an association between alcohol use and sexual assault (Abbey, 2002). ${ }^{15}$ our findings indicate that alcohol use does play a key role in sexual assault. Alcohol was the leading correlate associated with sexual assault which is consistent with the HBCU-CSA findings suggesting that women who reported getting drunk had higher chances of being victims of incapacitated sexual assault. ${ }^{19}$ Another correlate was prior victimization. It is more likely for victims of prior victimization to experience sexual assault later in their lifetime. This is also consistent with findings from the HBCU-CSA study reporting that being a victim of forced sexual assault before college was significantly associated with being a victim of forced sexual assault. ${ }^{19}$ Although a few men did report an occurrence of sexual assault, women were more likely to be sexually assaulted than men. Research suggests that there are barriers to reporting sexual assault and victims are more likely to report to friends or roommates. In addition, participants in this study indicated several reasons to not report which are comparable to findings from a study on barriers to reporting sexual assault.12, 21 Participant's reasons for not reporting include but are not limited to embarrassment, did not want family or friends to know, or being afraid of retaliation. Other reasons include lack of knowledge of how or where to report incidents of sexual assault. Victims were more likely to experience safety concerns and anxiety after sexual assault. Also, concerns with trusting the college administration to protect victims and follow the necessary steps of reporting was a barrier.

While not examined in the current study, one theoretical framework that may aid in understanding these findings is the Intersectionality Theory. This theory posits that "people are often disadvantaged by multiple sources of oppression: their race, class, gender identity, sexual orientation, religion, and other identity markers. Intersectionality recognizes that identity markers (e.g. "female" and "black") do not exist independently of each other, and that each informs the others, often creating a complex convergence of oppression". 22,23 Thus, the dominant group (e.g., men or campus officials) may be perceived as using power to normalize oppression within marginalized groups (e.g., women). In the case of sexual assault, women may be more likely to experience deleterious outcomes associated with assault, such as anxiety and safety concerns, due in part to not getting the type of support needed to address the assault for fear of not being believed by the current power structures or may not report for the same reasons (e.g., fear of retaliation and not trusting college administration).

\section{Limitations}

There are several limitations to this study. Given that this study was only done on one HBCU and the sample size was small, we cannot generalize the findings to other HBCU campuses. The response rate of the survey only represented $4 \%$ of the total student population.at the participating university. Also, the majority of participants were seniors which limit a representation of lowerclassman (particularly freshman) who are more likely to be victims of sexual assault. Since this was a self-report survey, we had to assume the accuracy of answers pertaining to sexual history as well as response bias. There was also missing data. This could have resulted from participant's option to skip questions, discomfort from answering the questions, or accurately recalling sexual history.

\section{CONCLUSIONS}

Sexual assault remains a problem on college campuses, especially among women. The significance of this study was to add to the existing body of literature by examining sexual assault at an HBCU. With the exception of the HBCU-CSA study, most past research addressing sexual assault primarily target PWIs, so this study aimed to eliminate that gap by adding to the extant research on sexual assault at HBCU's. Given that there is limited research on sexual assault in HBCU populations, future research could examine if there are differences among students attending a PWI and HBCU. This could allow researchers to determine if there are racial differences in sexual assault and its impact on students. Additional research should focus on other aspects of sexual assault such as consent and what prevention methods can be implemented to decrease and eventually eliminate sexual assault on college campuses. Addressing sexual consent is an integral part of understanding sexual assault. Within sexual consent, research could examine the role of alcohol in consenting to sexual activity. One key finding of this study was that alcohol was the only factor associated with sexual assault. Interventions should be created to help students reduce alcohol consumption while educating them about the consequences of drinking on their health and mental capacity. The results of this study also indicated the need for interventions to educate students about sexual assault and how to prevent it. Possible interventions could include self-defense courses and workshops that address sexual assault and prevention strategies. According to our study, a close friend other than a roommate was more likely to be told about the assault. Interventions should, therefore, target individuals who are told about incidents of sexual assault. Targeting these individuals may help better assist victims of sexual assault. Assistance could include helping the victim to report, provide them with resources such as counseling, medical examination facilities, or shelter if needed. It is important to make students feel comfortable about reporting to the police or other authority figures. Lastly, observations of university policies on sexual assault may address concerns of reporting. Students should learn as a freshman entering college where and who they can report incidents of sexual assault and be assured they will be treated fairly, attain proper help and safety. 


\section{ACKNOWLEDGMENTS}

This project was supported by the National Institutes of Health NIGMS-BUILD TL4GM1189742.

The authors thank Ms. Tanyka Barber and Ms. Emily Ralph in the Office of Diversity, EEO, Ebele Oranuba and the participants of the study.

\section{REFERENCES}

1. Centers for Disease Control and Prevention, National Center for Injury Prevention and Control, Division of Violence Prevention. (2016). Sexual violence: Definitions. Retrieved from https://www.cdc.gov/violenceprevention/sexualviolence/definitions.html

2. U.S. Department of Justice, Office of Violence Against Women (2017). What is sexual assault? Retrieved from https:// wnw.justice.gov/ ovw/sexual-assault

3. Rape, Abuse, and Incest National Network (2016). Campus sexual violence: Statistics. Retrieved from bttps: / / wnw. rainn.org/statistics/campus-sexual-violence

4. Jozkwoski, K.N., Peterson, Z.D., Sanders, S.A., Dennis, B., \& Reece, M. (2014). Gender differences in heterosexual college students' conceptualizations and indicators of sexual consent: Implications for contemporary sexual assault prevention education. Journal of Sex Research, 51, 904-916. doi: 10.1080/00224499.2013.792326

5. Breiding, M.J. (2014). Prevalence and characteristics of sexual violence, stalking, and intimate partner violence victimization — national intimate partner and sexual violence survey, United States, 2011. Washington, D.C. Morbidity and Mortality Weekly Report. Retrieved from https:// www.cdc.gov/mmwr/preview/ mmwrhtml/ss6308a1.htm

6. Walters, M.L., Chen, J. \& Breiding, M.J. (2013). National Intimate Partner and Sexual Violence Survey (NISVS): 2010 findings on victimization by sexual orientation. (Report No. 241083). Atlanta, GA. National Criminal Justice Reference Service. Retrieved from bttps:/ / wnw.ncirs.gov/App/Publications/abstract.aspx?ID=263171

7. Armstrong, E.A., Hamilton, L., \& Sweeny, B (2006). Sexual assault on campus: A multilevel, integrative approach to party rape. Social Problems, 53, 483-499. doi: 10.1525/sp.2006.53.4.483

8. Jordan, C.E., Combs, J.L., \& Smith, G.T. (2014). An exploration of sexual victimization and academic performance among college women. Trauma, Violence, \& Abuse, 15, 191-200. doi: 10.1177/1524838014520637

9. Sinozich \& Langton, (2014). Rape and sexual assault victimization among college females, 1995-2013. (Report No. 248471). Washington, D.C. U.S. Department of Justice. Retrieved from bttps:// assets.documentcloud.org/documents/1378364/ rsavcaf9513.pdf

10. Krebs, C.P., Linquist, C.H., Warner, T.D., Fisher, B.S., \& Martin, S.L. (2007). The campus sexual assault (CSA) study. (Report No. 221153). Rockville, MD. National Crime Justice Reference Service. Retrieved from https: / / wnw.ncirs.gov/ App/Publications/ abstract.aspx?ID $=243011$

11. Fisher, B.S. Cullen, F.T., \& Turner, M.G. (2000). The sexual victimization of college women. (Report No. 182369). Washington, D.C. National Institute of Justice. Retrieved from bttp://files.eric.ed.gov/fulltext/ED449712.pdf

12. Sable, M. R., Danis, F., Mauzy, D. L., \& Gallagher, S. K. (2006). Barriers to reporting sexual assault for women and men: perspectives of college students. Journal of American College Health, 55, 157-162. doi: 10.3200/JACH.55.3.157-162

13. Kilpatrick, D.G., Resnick, H.S., Ruggiero, K.J., Conoscenti, L.M., \& McCauley, J. (2007). Drug-facilitated, incapacitated, and forcible rape: A national study. (Report No. 219121). Washington D.C. National Crime Justice Reference Service.

14. Fisherk, B.S., Daigle, L.E., Cullen, F.T., \& Turner, M.G. (2003). Reporting sexual victimization to The police And others: Results from a national-level study of college women. Criminal Justice and behavior, 30, 6-38. doi: $10.1177 / 0093854802239161$

15. Abbey, A. (2002). Alcohol-related sexual assault: A common problem among college students. Journal of Studies on Alcohol, Supplements, 14, 118-128. doi: 10.15288/jsas.2002.s14.118

16. Abbey, A., McAuslan, P Ross, L.T. (1998). Sexual assault perpetration by college men: The role of alcohol, misperception of sexual intent, and sexual beliefs and experiences. Journal of Clinical and Social Psychology, 17, 167-195. doi: $10.1521 / j s c p .1998 .17 .2 .167$

17. Krebs, C.P., Barrick, K., Lindquist, C.H., Crosby, C.M., Boyd, C., \& Bogan, Y. (2011). The sexual assault of undergraduate women at historically black colleges and universities (HBCUs). Journal of Interpersonal Violence, 26, 3640-3666. doi: $10.1177 / 0886260511403759$

18. Lindquist, C. H., Barrick, K., Krebs, C., Crosby, C. M., Lockard, A. J., \& Sanders-Phillips, K. (2013). The context and consequences of sexual assault amongst undergraduate women and historically black colleges and universities (HBCUs). Journal of Interpersonal Violence, 28, 2437-2461. doi: 10.1177/0886260513479032

19. Krebs, C.P., Linquist, C.H., Barrick, K. (2011). The Historically Black, College and University Campus Sexual Assault (HBCUCS A) Study. (Report No. 233614). Washington, D.C. National Crime Justice Reference Service.

20. Not Alone: The First Report of the White House Task Force to Protect Students from Sexual Assault (April, 2014). Washington, D.C. Retrieved from bttps://wnww.justice.gov/arcbives/ovw/protecting-students-sexual-assault

21. YW Boston. (2017, March 29). What is intersectionality and what does it have to do with me [Web log message]. Retrieved from https: / /wnw.ywboston.org/2017/03/what-is-intersectionality-and-what-does-it-bave-to-do-with-me/ 
22. Cole, E. R. (2009). Intersectionality and research in psychology. American Psychologist, 64(3), 170-180. bttp:/ / dx.doi.org/10.1037/a0014564

23. Lindquist, C.H., Crosby, C.M., Barrick, K., Drebs, C.P., \& Settles-Reaves, B. (2016). Disclosure of sexual assault experiences among undergraduate women at historically black colleges and universities (HBCUs). Journal of American College Health, 64(6), 469-480. doi: 10.1080/07448481.2016.1181635

\section{ABOUT THE STUDENT AUTHORS}

Deshawn Collington recently graduated from Morgan State University with a Bachelor of Science in Psychology.

Markea Carter recently graduated from Morgan State University with a Bachelor of Science in Psychology.

Aliyah Tolliver graduated from Morgan State University with a Bachelor of Science in Psychology and received a Master of Science in Clinical Psychology from the University of Maryland, College Park.

\section{PRESS SUMMARY}

This article examines sexual assault among African American college students by providing prevalence rates, correlates, outcomes, and barriers to reporting associated with sexual assault. Findings suggest that sexual assault remains a problem and is prevalent on an HBCU campus. 